\title{
Internalization of Type 1 Complement Receptors and De Novo Multivesicular Body Formation during Chemoattractant-induced Endocytosis in Human Neutrophils
}

\author{
Melvin Berger, Erica Wetzler, J. Thomas August, ${ }^{\star}$ and Alan M. Tartakoff \\ Departments of Pediatrics and Pathology, Case Western Reserve University School of Medicine, Cleveland, Ohio 44106; and \\ * Department of Pharmacology and Molecular Science, Johns Hopkins University School of Medicine, Baltimore, Maryland 21205
}

\begin{abstract}
Upon activation of human neutrophils by chemoattractants, functionally important proteins are rapidly transported from intracellular granules and storage vesicles to the plasma membrane. This is accompanied by a marked increase in the rate of endocytosis and by ligand-independent internalization of type 1 complement receptors (CR1). To define the pathway of endocytosis, we used gold-conjugated BSA in a pulse-chase protocol. This tracer was initially internalized into small endocytic vesicles which rapidly traversed the cytoplasm and coalesced to form large, conspicuous multivesicular bodies. Within $5 \mathrm{~min}$ after addition of the chemoattractant, multivesicular bodies contained $>60 \%$ of the cell-associated BSA-gold. CR1 colocalized with the endocytic tracer in both the early endosomes and multivesicular bodies. In unstimulated cells, there was much less uptake of BSA-gold and multivesicular bodies were rarely seen. Using the acidotropic amine, DAMP, and anti-DNP antibodies, we found that the multivesicular bodies were acidified but the early endosomes did not concentrate DAMP. Neither the early endosomes nor the multivesicular bodies initially contained the lysosomal membrane antigens hLAMP 1 or 2, but hLAMP-positive structures subsequently joined the multivesicular bodies. The rapid activation of the endocytic pathway upon stimulation of neutrophils allowed us to visualize the de novo formation and maturation of multivesicular bodies. Our observations suggest that vesicles containing ion pumps and acid hydrolases fuse with multivesicular bodies, giving them characteristics of lysosomes, and that these are the probable sites of degradation of CR1. The observations do not support models which would require transport of CR1 from multivesicular bodies to defined, pre-existing lysosomes for degradation. (J. Clin. Invest. 1994. 94:11131125.) Key words: endocytosis - neutrophil • complement receptor - chemoattractant
\end{abstract}

Address correspondence to Dr. Melvin Berger, Department of Pediatrics, Rainbow Babies and Children's Hospital, 2074 Abington Rd., Cleveland, $\mathrm{OH} 44106$. 1994.

Received for publication 10 May 1994 and in revised form 29 March

\section{J. Clin. Invest.}

(C) The American Society for Clinical Investigation, Inc.

$0021-9738 / 94 / 09 / 1113 / 13 \quad \$ 2.00$

Volume 94, September 1994, 1113-1125

\section{Introduction}

Activation of human neutrophils by chemoattractants induces dramatic changes in their functional capabilities, as receptors and adhesion molecules are rapidly brought to the surface of the cell and the microbicidal oxidase system is assembled from components stored in different intracellular compartments (1$5)$. Several of these proteins are stored in resting cells in the membranes of the characteristic neutrophil granules $(1,2)$, while others are stored in the membranes of smaller vesicular structures $(4,6,7)$. Fusion of the membranes of these intracellular structures with the plasma membrane thus represents a major pathway of protein translocation during cell activation. Activation of neutrophils by chemoattractants is also accompanied by a rapid increase in the rate of fluid phase pinocytosis (8-10). The internalization of the membrane that forms the pinocytic vesicles may serve to partially balance the exocytotic flow of membrane to the cell surface.

Within minutes of stimulation of resting neutrophils by the chemotactic peptide $N$-formyl-Met-Leu-Phe (f MLP), type 1 complement receptors (CR1) ${ }^{1}$ are transported from the membranes of small vesicles to the plasma membrane, increasing their surface expression up to 10 -fold $(3,6,11,12)$. This chemoattractant also induces ligand-independent internalization of $\operatorname{CR} 1(12,13)$, and we have reported that the internalized receptors accumulate in large, distinctive multivesicular bodies (6, 13). These structures are not easily seen in resting neutrophils that have not been exposed to chemoattractants, but in activated cells they are conspicuous and serve as major sites of internalization of markers of fluid phase pinocytosis $(6,14,15)$.

Many questions concerning the formation and function of multivesicular bodies remain unanswered. They have often been considered to be intermediate sorting structures along the endocytic pathway, although they may also contain acid hydrolases (16-19). Some investigators propose that they are stable prelysosomal sorting structures and that proteins within their interior must be transported to lysosomes if they are to be degraded (20), while others propose that functionally similar structures form de novo during endocytosis and then mature by the addition of proteins which give them the characteristics of late endososmes or lysosomes (16). The neutrophil provides a unique system for evaluating these hypotheses because the endocytic pathway is quiescent in resting cells but can be rapidly activated

1. Abbreviations used in this paper: CR1, complement receptor type 1; DAMP, 3-(2,4-dinitroanilino)-3'-amino- $N$-methyldipropylamine; f MLP, $N$-formyl-methionyl-leucyl-phenylalanine; hLAMP, human lysosomal membrane protein. 

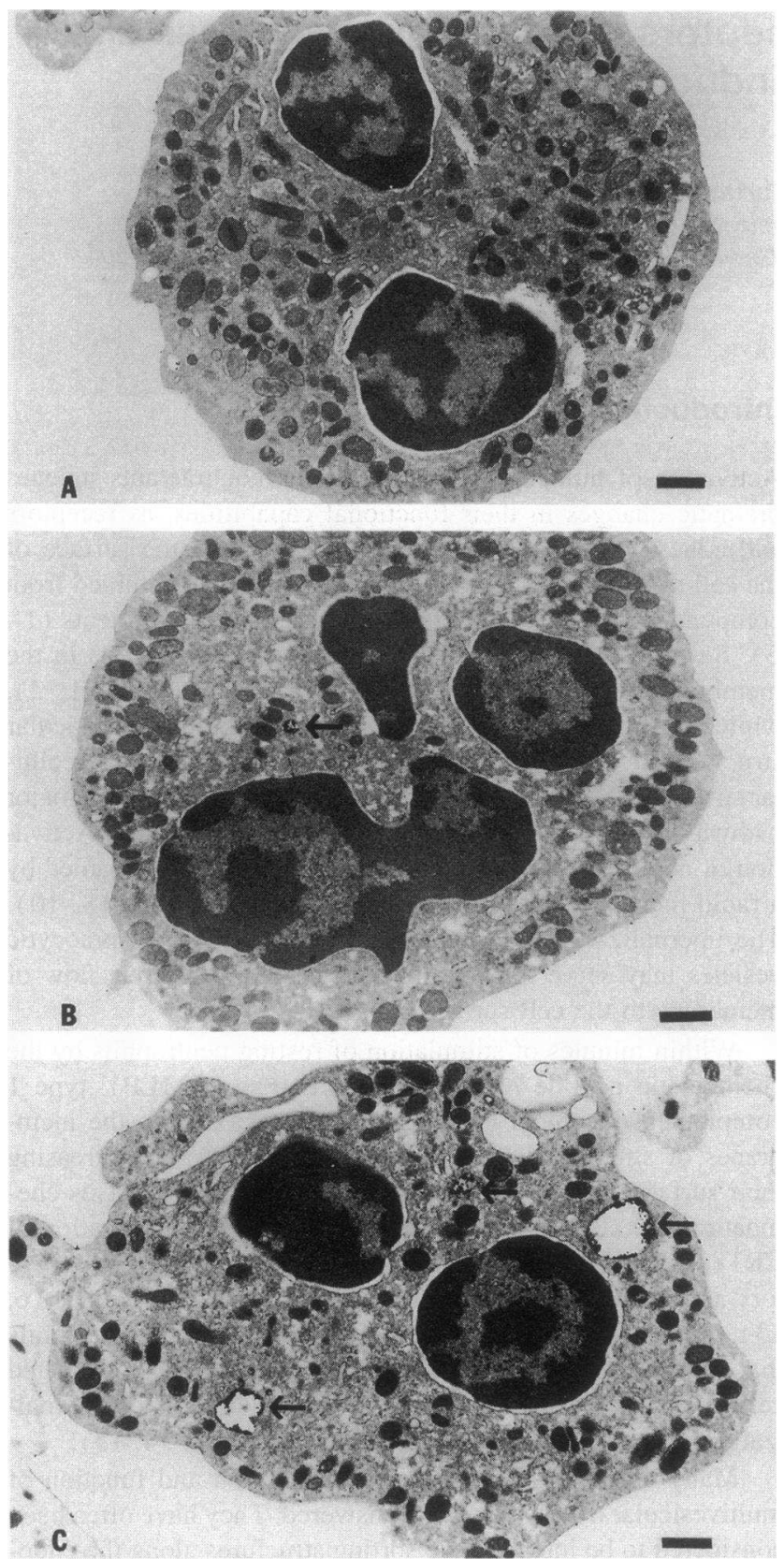

Figure 1. Neutrophils were incubated for $20 \mathrm{~min}$ with gold-BSA at $0^{\circ} \mathrm{C}$ $(A), 37^{\circ} \mathrm{C}$ in buffer alone $(B)$, or $37^{\circ} \mathrm{C}$ with $\mathrm{f} \mathrm{MLP}(C)$. Arrows show accumulations of endocytosed gold-BSA in multivesicular bodies. Bars, $0.1 \mu \mathrm{m}$.

by chemoattractants, resulting in the de novo appearance of large, conspicuous multivesicular bodies.

In this report, we have studied the pathway of chemoattractant-induced endocytosis by using colloidal gold conjugated to bovine serum albumin as a marker of fluid phase pinocytosis. Pulse-chase analysis of the kinetics of movement of the initial small endocytic vesicles across the cell and their apparent coalescence into multivesicular bodies showed that this was a rapid process. Within $5 \mathrm{~min}$ after stimulation $>60 \%$ of the cell associated gold was found in large conspicuous multivesicular bodies. In the absence of $\mathrm{fMLP}$ there was much less uptake of the gold conjugate, and only a few small multivesicular bodies were formed. Using dinitroanilino-amino- $N$-methyl dipropylamine (DAMP) and antibodies against dinitrophenol, we found that the multivesicular bodies became markedly acidified while the early endosomes did not appreciably concentrate the amine. Neither the early endosomes nor multivesicular bodies initially contained the lysosomal membrane markers hLAMP 1 or 2 . However, hLAMP positive structures subsequently fused with the multivesicular bodies, giving the latter a positive reaction as well. Our results thus suggest that in activated neutrophils, multivesicular bodies form by the coalescence of small endocytic vesicles. They subsequently mature by acquiring proton pumps and acid hydrolases. The multivesicular bodies themselves are thus the likely sites of intracellular degradation of CR1, rather than an intermediate compartment from which internalized receptors are transported to lysosomes for degradation.

\section{Methods}

Cells. Human neutrophils were isolated from heparinized peripheral blood of normal donors using Percoll density gradients as previously described $(3,21)$. Contaminating erythrocytes were removed by lysis with hypotonic saline, and PMN were washed in Hanks' Balanced Salts Solution (HBSS) without $\mathrm{Ca}^{2+}$ or $\mathrm{Mg}^{2+}$ containing $0.1 \%$ gelatin and held at $0^{\circ} \mathrm{C}$ in this solution until beginning experimental incubations. Cells prepared in this way are routinely $>95 \%$ pure by microscopic examination, and $>95 \%$ viable as determined by trypan blue exclusion.

Endocytic tracers and antibodies. BSA or ovalbumin were coupled to $20 \mathrm{~nm}$ colloidal gold as described previously (22). A mixture of two monoclonal antibodies (3D9 and C543, originally obtained from Drs. John O'Shea and Robert Schreiber, respectively) that bind distinct epitopes on the human $\mathrm{C} 3 \mathrm{~b} / \mathrm{C} 4 \mathrm{~b}$ receptor (complement receptor type 1 , CR1), was used to identify that protein. Their use for immunoelectron microscopic localization of CR1 in human neutrophils has been described previously (6). Monoclonal antibodies produced by hybridomas H5G11 and H4B4, which recognize the 120-kD human lysosomal membrane proteins hLAMP1 and hLAMP2, have been described previously (23). DAMP [3-(2,4-dinitroanilino)-3'-amino- $N$-methyldipropylamine ] and monoclonal antibody to dinitrophenol were obtained from Oxford Biomedical Research Inc. (Oxford, MI). Rabbit anti-mouse IgG was purchased from Cappel Laboratories (Durham, NC) and 15 nm gold-conjugated goat anti-rabbit IgG (Auroprobe GAR G15) was purchased from Amersham (Chicago, IL). Gold ( $5 \mathrm{~nm}$ ) conjugated goat anti-mouse IgG was purchased from Pella, Inc. (Redding, CA).

Stimulation of neutrophils and characterization of endocytosis. Neutrophils were preincubated at $1-2 \times 10^{6} / \mathrm{ml}$ at $37^{\circ} \mathrm{C}$ for $15 \mathrm{~min}$ in HBSS. BSA-gold was added to a final protein concentration of $0.5 \mathrm{mg} /$ $\mathrm{ml}$. Cells were then immediately stimulated by the addition of $\mathrm{f}$ MLP at a final concentration of $10^{-8} \mathrm{M}$. The $\mathrm{f} \mathrm{MLP} \mathrm{had} \mathrm{been} \mathrm{stored} \mathrm{at}-80^{\circ} \mathrm{C}$ as a $10^{-3} \mathrm{M}$ stock solution in DMSO. Unstimulated controls were run in parallel and contained the same concentration of BSA-gold but no f MLP. To study the kinetics of endocytosis, a pulse-chase protocol was employed. After 2 min of incubation with BSA-gold and $f$ MLP (pulse), cells were washed twice with HBSS by centrifugation at $1,000 \mathrm{rpm}$ for 5 min at $4^{\circ} \mathrm{C}$, then returned to $37^{\circ} \mathrm{C}$ in HBSS containing $f$ MLP but lacking BSA-gold for varying intervals (chase). The control which was not stimulated with $\mathrm{f}$ MLP during the first incubation was returned to HBSS without $f$ MLP. At the end of each designated time period, aliquots of each cell suspension were fixed by addition to an equal volume of $4 \%$ glutaraldehyde at $0^{\circ} \mathrm{C}$. After 30 to $60 \mathrm{~min}$, cells were washed twice with PBS, treated with $1 \% \mathrm{OsO}_{4}$ in $50 \mathrm{mM}$ cacodylate, $\mathrm{pH} 7.4$, for $30 \mathrm{~min}$ at room temperature, dehydrated, and embedded in Spurr's resin for ultrathin sectioning. Transmission EM was then performed with a JEOL $100 \mathrm{CX}$ electron microscope.

Identification of acidified compartments. Cells were prepared and 

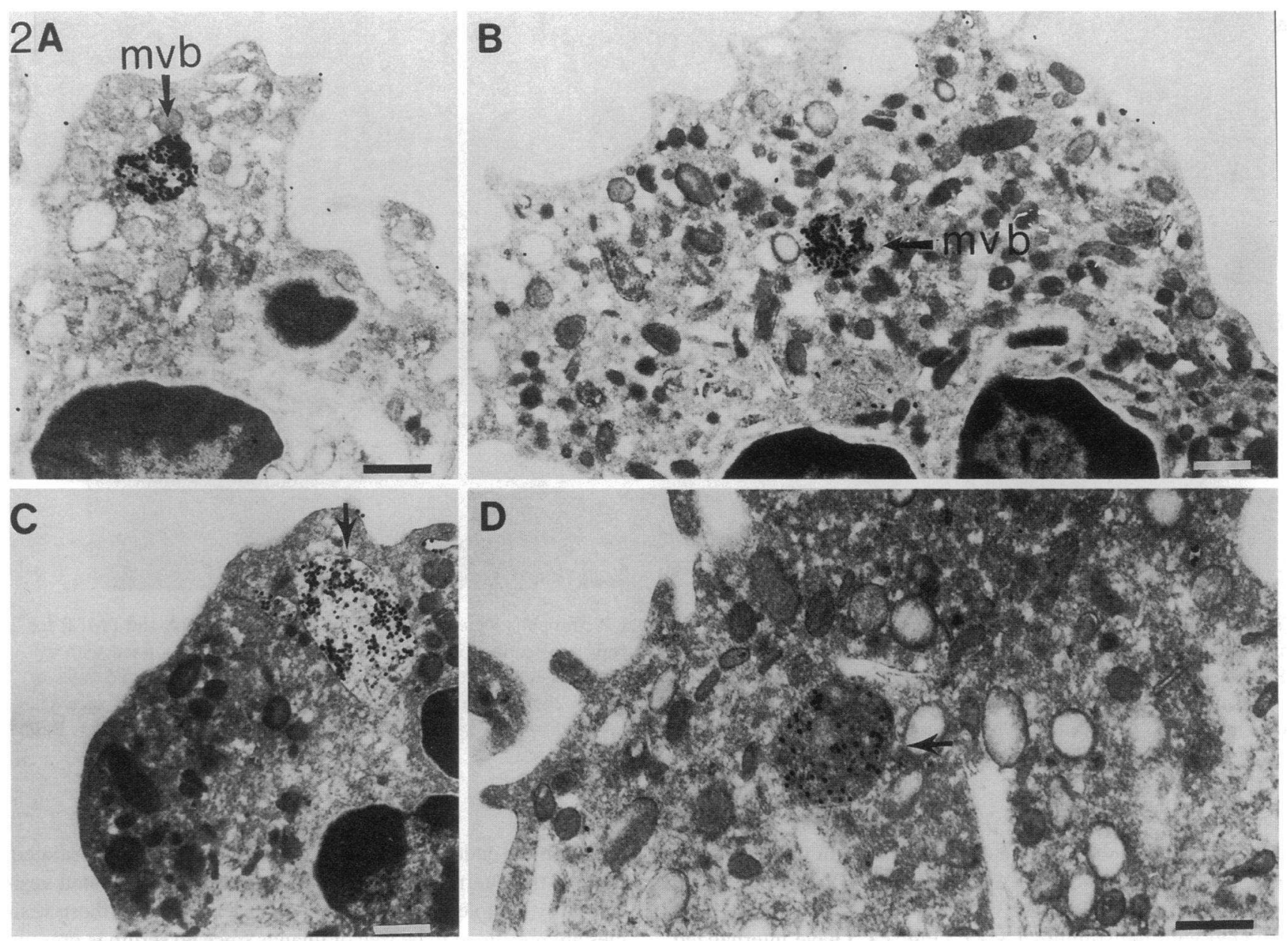

Figure 2. Neutrophils were activated with $\mathrm{fMLP}$ for $1 \mathrm{~h}$ in the presence of markers of fluid endocytosis, with or without excess unconjugated carrier protein. $(A)$ Gold-BSA $(0.5 \mathrm{mg} / \mathrm{ml}) ;(B)$ gold-BSA $(0.5 \mathrm{mg} / \mathrm{ml})+$ free BSA $(50 \mathrm{mg} / \mathrm{ml}) ;(C)$ gold-ovalbumin $(0.5 \mathrm{mg} / \mathrm{ml}) ;(D)$ goldovalbumin $(0.5 \mathrm{mg} / \mathrm{ml})+$ free ovalbumin $(50 \mathrm{mg} / \mathrm{ml}) . m \nu b$, multivesicular body. Bars, $0.5 \mu \mathrm{m}$.

activated in the presence of the endocytic tracer using the pulse chase protocol as above, but $30 \mu \mathrm{M}$ DAMP was included simultaneously with f MLP in both the pulse and chase phases. In some experiments, to control for specificity, $37 \mathrm{mM} \mathrm{NH}{ }_{4} \mathrm{Cl}$ was also included. After the appropriate duration of incubation at $37^{\circ} \mathrm{C}$, cells were fixed by the immediate addition of ice-cold $1 \%$ glutaraldehyde $/ 5 \mathrm{mM} \mathrm{CaCl}_{2} / 0.1 \mathrm{M}$ cacodylate, $\mathrm{pH}$ 7.4. They were washed once and incubated in the same solution for $1 \mathrm{~h}$ on ice, then washed twice in $0.1 \mathrm{M}$ cacodylate/0.1 M $\mathrm{NH}_{4} \mathrm{Cl}$, and stored at $4^{\circ} \mathrm{C}$ overnight in $0.1 \mathrm{M}$ cacodylate. Cells were post-fixed in $1 \% \mathrm{OsO}_{4} / 1 \%$ potassium ferrocyanide $/ 0.1 \mathrm{M}$ cacodylate, $\mathrm{pH} 7.4$, for $2 \mathrm{~h}$ at room temperature, then washed twice with $0.1 \mathrm{M}$ cacodylate and twice with $\mathrm{H}_{2} \mathrm{O}$. They were then incubated in $0.05 \%$ tannic acid (Sigma type T-0125; Sigma Chemical Co., St. Louis, MO) in water for 15 min, washed twice with $\mathrm{H}_{2} \mathrm{O}$, dehydrated, and embedded in LR-white resin.

Preparation of ultrathin cryosections for immunoelectron microscopy. For localization of CR 1 or LAMP, cells were activated with $\mathrm{A}$ MLP in the presence of gold-BSA, as above, and then fixed by the addition of ice cold $2 \%$ paraformaldehyde $/ 0.05 \%$ glutaraldehyde $/ 0.1 \%$ sucrose in $10 \mathrm{mM}$ phosphate buffer, $\mathrm{pH}$ 7.4. Cells were then washed and resuspended in the same solution and held on ice for $90 \mathrm{~min}$, embedded in $10 \%$ gelatin (24), and stored in $2.3 \mathrm{M}$ sucrose frozen on liquid $\mathrm{N}_{2}$. Ultrathin sections were cut on a Reichert Ultracut FC E at -95 to $-100^{\circ} \mathrm{C}$ and placed on Formvar coated nickel grids. Grids were held on $2 \%$ gelatin overnight at $4^{\circ} \mathrm{C}$. Aldehydes were further quenched with
$20 \mathrm{mM}$ glycine in Tris-buffered saline (TBS) $\mathrm{pH} 7.6$, using three 10min incubations, and sections were blocked using $1 \%$ ovalbumin in TBS containing $10^{-4} \mathrm{M}$ phenylmethylsulfonylfluoride (PMSF) for 60 $\min$. Sections were stained with the anti-CR1 or anti-hLAMP monoclonal antibodies described above, or with non-immune mouse IgG1 (MOPC 21; Sigma Chemical Co.) in TBS containing $1 \%$ ovalbumin, $0.2 \%$ cold water fish gelatin (Sigma Chemical Co.) and $10^{-4} \mathrm{M}$ PMSF for $90 \mathrm{~min}$, then washed four times in TBS-PMSF. Sections were then stained with $5 \mathrm{~nm}$ gold conjugated goat anti-mouse IgG for $90 \mathrm{~min}$, washed again with TBS-PMSF, and four additional times with distilled $\mathrm{H}_{2} \mathrm{O}$. The sections were postembedded in a 9:1 mixture of methylcellulose (Sigma Chemical Co.) and $3 \%$ uranyl acetate $(25,26)$. All sections were examined with a JEOL $100 \mathrm{CX}$ transmission electron microscope.

\section{Results}

Use of BSA-gold as a tracer of fluid phase pinocytosis. The use of gold conjugates to trace fluid phase pinocytosis was initially tested in preliminary experiments. Fig. 1 shows the effects of activation of the cells on the uptake and distribution of BSAgold tracer during 20 min of continuous incubation. Resting cells maintained at $0^{\circ} \mathrm{C}$ show little internalization of BSA-gold (Fig. $1 \mathrm{~A}$ ). Cells incubated at $37^{\circ} \mathrm{C}$, which may undergo some 

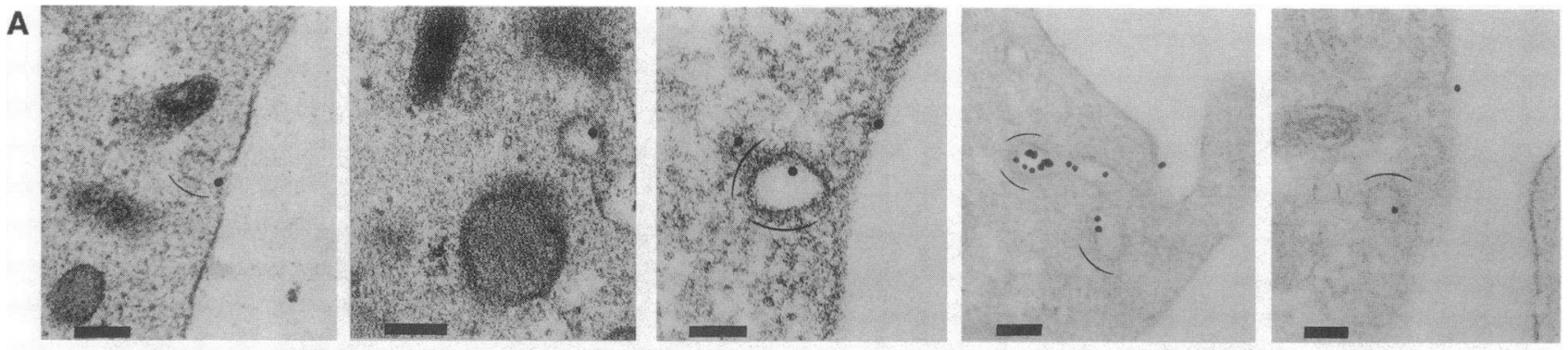

B
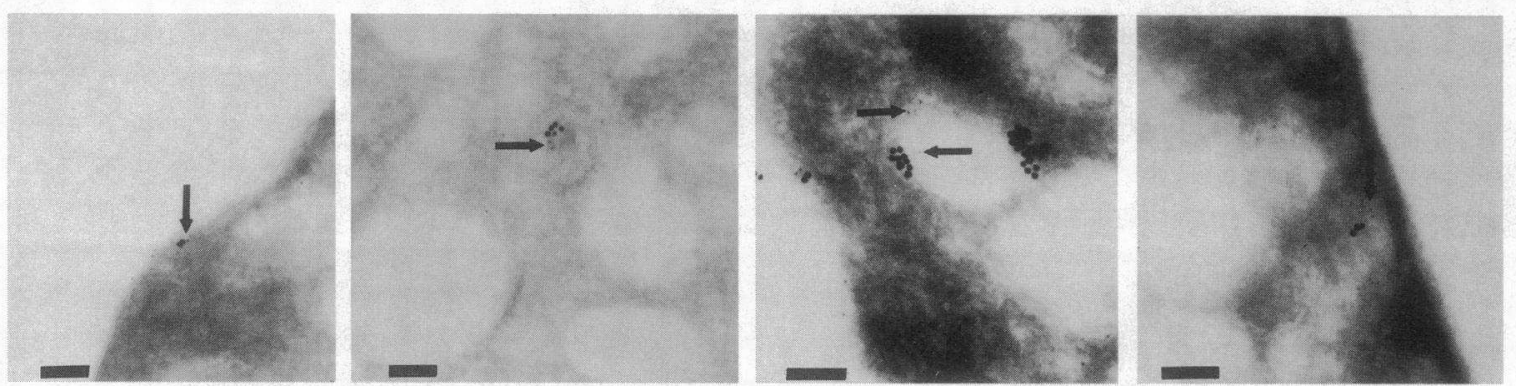

Figure 3. Detail of structures involved in initial internalization of BSA-gold. Neutrophils were incubated with $20 \mathrm{~nm}$ gold-BSA and $\mathrm{f}$ MLP for 2 min then washed twice with HBSS, fixed, and prepared for electron microscopy as described in Methods. (A) Standard sections fixed with $4 \%$ glutaraldehyde and examined by transmission EM to characterize early endocytic vesicles. Arcs drawn on micrographs indicate coated areas of membrane/vesicle. $(B)$ Ultrathin cryosections stained for CR1. Fixation was with $2 \%$ paraformaldehyde, $0.05 \%$ glutaraldehyde, $0.1 \%$ sucrose. Anti-mouse IgG conjugated with $5 \mathrm{~nm}$ gold was used to identify anti-CR1 antibodies (arrows). $20 \mathrm{~nm}$ gold-BSA is the endocytic tracer. Bars, $0.1 \mu \mathrm{m}$.

activation even in the absence of specific stimuli $(3,11)$, show modest internalization of BSA-gold (Fig. $1 B$ ), most of which is contained in a single small vesicle (arrow). In contrast, cells activated with the stimulus f MLP (Fig. $1 C$ ) have internalized large amounts of BSA-gold, most of which is contained in three large structures (arrows) which themselves appear to contain multiple smaller vesicles, hence their designation as multivesicular bodies. All of these cells show scattered BSA-gold particles on their plasma membrane. To be sure that the BSA-gold was a suitable tracer of fluid phase pinocytosis and not an indicator of specific receptor mediated endocytosis, we compared the fate of ovalbumin-gold with BSA-gold incubated with neutrophils for $60 \mathrm{~min}$ in the presence of $\mathrm{f}$ MLP. Both tracers gained access to the same intracellular compartments, with little accumulation at the cell membrane (Fig. 2). The modest binding of the tracers to the cell membrane was shown to be non-specific by the addition of a 100-fold excess of free soluble BSA or ovalbumin with the respective gold conjugate during stimulation of PMN with $f$ MLP. The excess free protein did not reduce the surface labeling or uptake of either conjugate, suggesting that this uptake was not mediated by a specific, saturable receptor (Fig. 2, $B$ and $D)$. Some variability in the size and apparent density of multivesicular bodies may be seen in different cells as in Fig. 2, $C$ vs. $D$, and even within the same cell (Fig. $1 C$ ).

To study the route by which the endocytic tracers accumulate in multivesicular bodies, we performed time-course and pulse-chase experiments. The cellular structures involved in the initial uptake of BSA-gold conjugates were examined by transmission EM of osmium stained sections of cells incubated for 2 min with BSA-gold and f MLP. Most of the early endocytic invaginations and small peripheral vesicles containing the tracer include coated areas of membrane (Fig. 3 A). Thus, although the endocytosis of BSA-gold is not receptor mediated most of the internalization involves coated pits and coated vesicles. Any complement receptors which are present in these vesicles are presumed to be free of ligands since no serum is present.

Since our previous studies indicated that CR1 undergoes ligand-independent internalization in response to f MLP stimulation (13), we used immunogold staining to determine whether CR 1 and the fluid phase tracer shared the same pathway of endocytosis. As shown by the arrows in Fig. $3 \mathrm{~B}$, this does appear to be the case, since small round vesicles carrying 20 nm BSA-gold stained positively for CR1 ( $5 \mathrm{~nm}$ gold, arrows). These appear distinct from the vesicles in which CR1 is stored in resting cells, which are irregularly ovoid in shape and most of which are not near the cell surface (6).

Kinetics of fluid phase endocytosis. A pulse-chase protocol, in which the tracer was present only during the first two minutes of chemoattractant stimulation, was used to define the pathway and kinetics of endocytosis. As shown in Fig. 4, at the end of the 2-min pulse, most of the intracellular tracer was in small peripheral vesicles (arrowheads). Some of the vesicles had already traversed the cytoplasm and were no longer near the periphery of the cell, as shown by the arrows in Fig. $4 \mathrm{~B}$. Although some small multivesicular bodies were visible in some cells at this early time point (Fig. 4 A, asterisk), little or no gold conjugate was present in these structures, and we speculate that they may have been formed during previous activation events which occurred in vivo or during preparation of the cells.

The movement of the small vesicles across the cytoplasm was rapid-by $5 \mathrm{~min}$ of chase only a few labeled vesicles were visible near the periphery of the cell and $50-60 \%$ of the internalized gold-BSA was already in multivesicular bodies (Fig. 5). The results of the pulse-chase experiments are in 

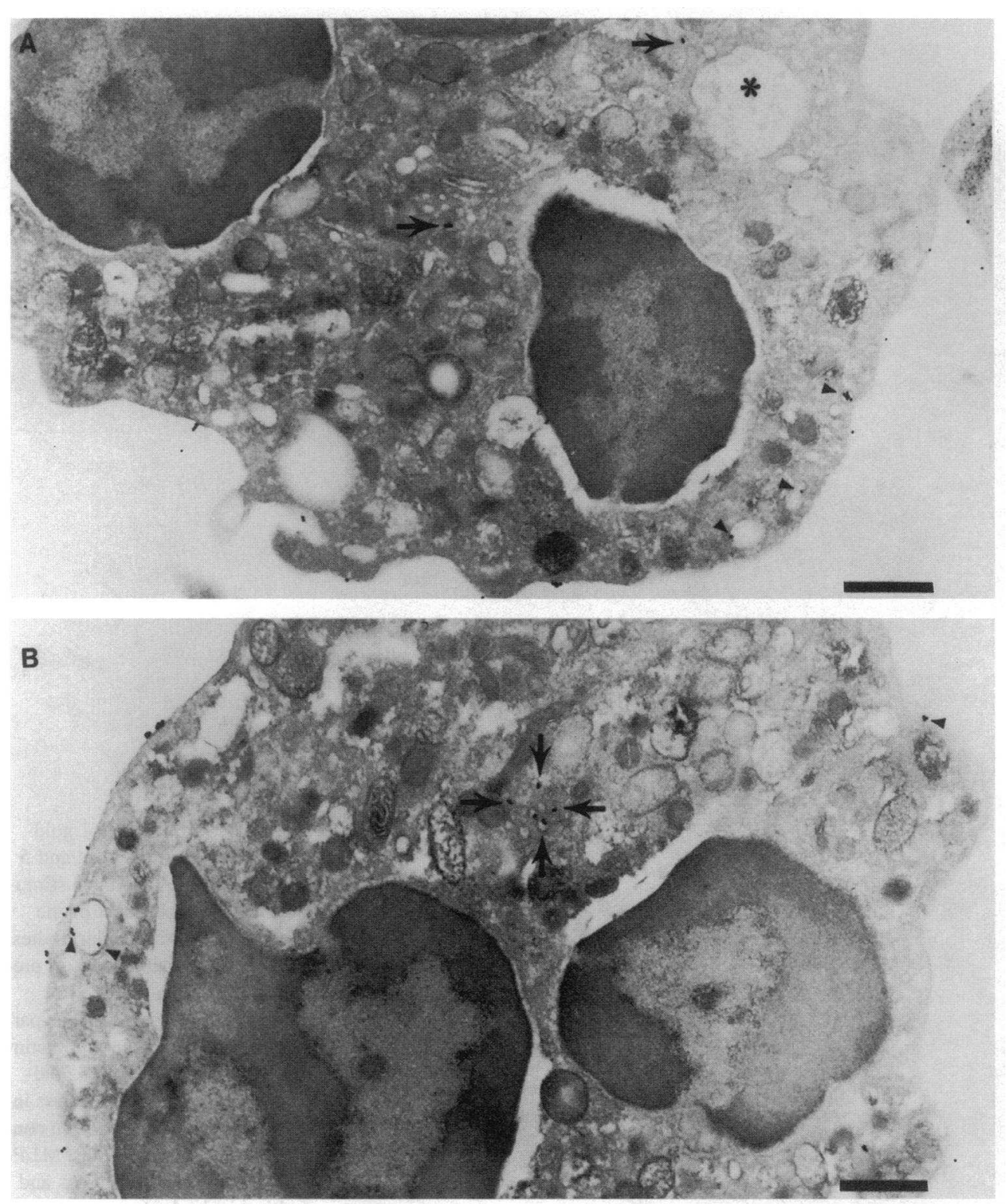

Figure 4. Localization of endocytic tracer at end of a 2-min pulse. Cells prepared as in Fig. 3 $A$. (A) Gold-BSA particles in peripheral vesicles are shown by arrowheads. Vesicles deeper in cytoplasm are indicated by arrows. Pre-existing multivesicular body, shown by asterix, does not contain any tracer. $(B)$ Tracer-containing vesicles that have traversed cytoplasm (arrows) appear to be coalescing. Bars, $0.5 \mu \mathrm{m}$. contrast to Figs. 1 and 2 in which the stimulus- $\mathrm{fMLP}$ and the gold-BSA were present continuously and in which gold-BSA continued to be internalized into peripheral structures at 20 and $60 \mathrm{~min}$ of incubation. The process of coalescence of endocytic vesicles into multivesicular bodies continued rapidly, such that by $25 \mathrm{~min}$ of chase, $>80 \%$ of the tracer was in the latter structures (Fig. 6). CR1 (5 nm gold) continued to follow the same intracellular pathway as the fluid phase tracer, and can be clearly visualized on the membranes of the $20 \mathrm{~nm}$ gold-BSAcontaining vesicles inside the multivesicular body (Fig. 7). In cells which were not stimulated by $\mathrm{f}$ MLP, but may have undergone some "spontaneous" activation when they were incubated at $37^{\circ} \mathrm{C}$, small multivesicular bodies also contained tracer, but the overall uptake was much less than in stimulated cells (Fig. $5 B$ and $6 C$ ). At $1 \mathrm{~h}$ and longer intervals, most of the goldBSA was found in large conspicuous multivesicular bodies, of which one or two were visible in most sections (Fig. 8). As seen in Fig. $8 \mathrm{~A}$ and also in some other images (i.e., Fig. 1 $C)$, there may be some variability in the appearance of these structures even in a single cell. There was no evidence of formation of dense residual bodies or other structures at later periods, most of the gold continued to be present in multivesicular bodies such as those present after $4 \mathrm{~h}$ (Fig. $8 \mathrm{~B}$ ). A summary of this kinetic analysis is provided in Fig. 9.

Acidification of endocytic structures. To determine the stage at which endocytic structures were acidified, we used the acidotropic amine, DAMP, and anti-DNP antibodies (27-29). The small peripheral vesicles that initially contain the endocytic tracer after the 3-min pulse with BSA-gold were not sufficiently acidified to concentrate the amine, and these structures did not become more acidified as they traversed the cell (Fig. $10 \mathrm{~A}$ ). After 45 min of chase (Fig. $10 \mathrm{~B}$ ), multivesicular bodies containing BSA-gold (20 nm gold) from the initial pulse were much more acidified and stained positively for DAMP (arrows, $5 \mathrm{~nm}$ gold). The lack of staining of the early endocytic vesicles is not because there was insufficient time for DAMP to accumulate in these structures, since several types of granules which had not received endocytic tracer were labelled with DAMP 

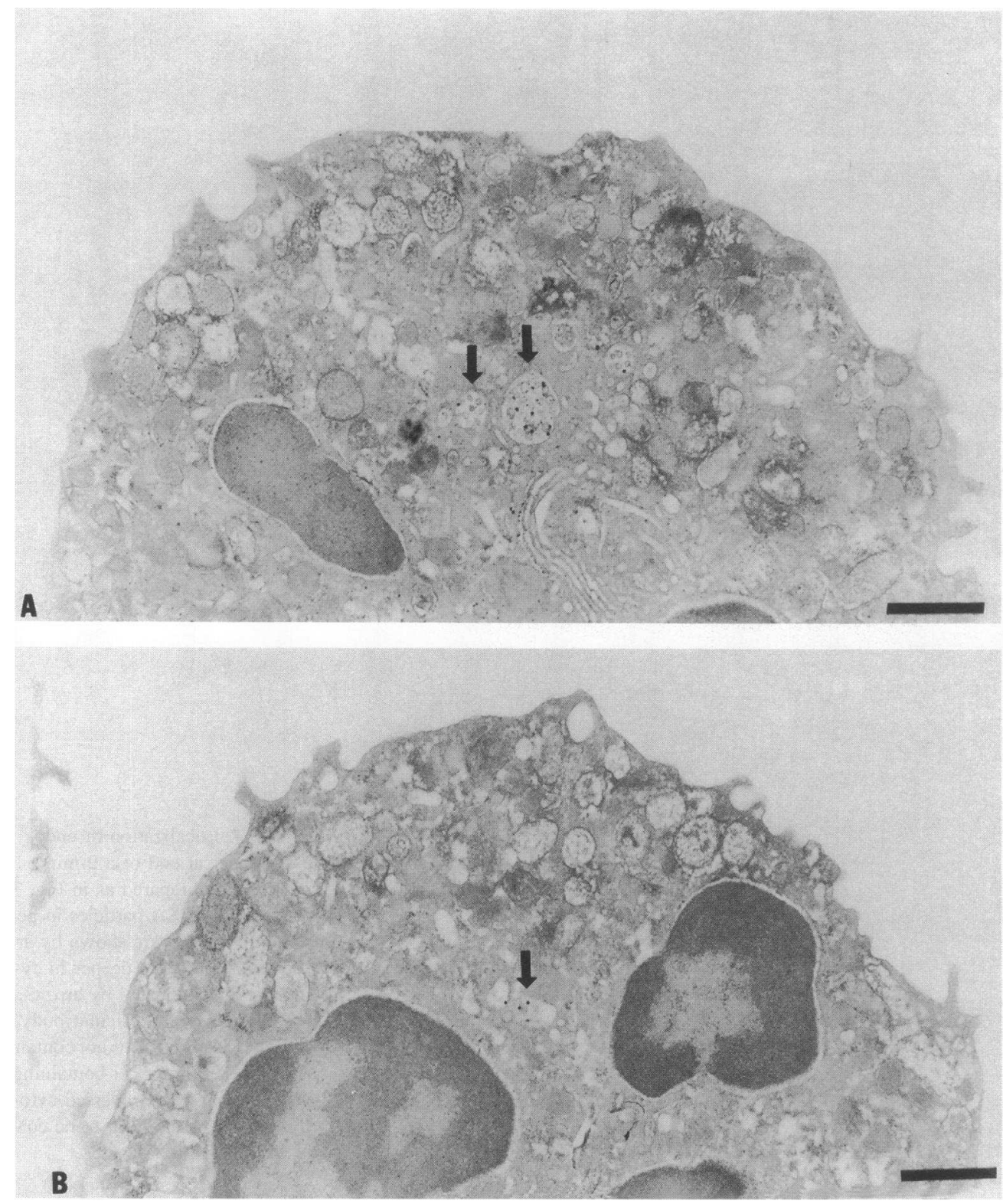

Figure 5. Localization of goldBSA after 2 min of pulse and 5 min of chase. $(A)$ In cells stimulated with $\mathrm{MLP}$, most of the tracer is in multivesicular bodies (arrows). A small amount of precipitate is visible scattered

throughout the cell, but those particles are smaller than and distinguishable from the larger goldBSA particles in the structures indicated by the arrows. $(B)$ In control cells not treated with I MLP, uptake of gold is much less and multivesicular body is much less distinct (arrow). Bars, $0.5 \mu \mathrm{m}$.

even at the earliest time points studied (Fig. 10 A, stars), and since peripheral vesicles were not DAMP positive at later time points (not shown). This increase in acidification of late endocytic structures is consistent with a model in which the early endocytic vesicles lack the machinery necessary for acidification but later acquire the pumps and/or channels required for this activity, possibly as a result of additional membrane fusion. In cells which were incubated at $37^{\circ} \mathrm{C}$ but were not stimulated with $f$ MLP, acidification of granules and the occasional preexisting multivesicular bodies was still apparent (not shown). Specificity of the staining with DAMP and anti-DNP was demonstrated by controls in which $37 \mathrm{mM} \mathrm{NH} \mathrm{NH}_{4} \mathrm{Cl}$ was included with DAMP and in controls which the MOPC 21 myeloma protein was substituted for the anti-DNP antibody. In both of these situations, there was no gold labeling (not shown).

Addition of lysosomal membrane proteins. To determine when endocytosed material came into contact with lysosomes, we used the pulse-chase protocol described above, and stained with a mixture of monoclonal antibodies to the two similar human lysosomal membrane antigens hLAMP 1 and hLAMP 2. Early in the chase, these antigens were present in intracellular granules and vesicles (Fig. 11), but they were not found in areas of the plasma membrane where the endocytic tracer was being internalized or in the small endocytic vesicles (Fig. 11, $A$ and $B$, arrowheads). At 10 to $15 \mathrm{~min}$ of chase, most of the endocytic tracer was in multivesicular bodies, but these contained only minimal amounts of hLAMP (Fig. 12, $A$ and $B$ ). At $25 \mathrm{~min}$ and later, there was positive staining for the hLAMP antigens on the limiting membrane as well as on internal vesicles in multivesicular bodies that had received the endocytic tracer. Although there is no clear evidence of membrane fusion, a number of sections suggest that hLAMP positive granules are joining multivesicular bodies (Fig. 13, $A$ and $B$ ). By 1 hour, all of the multivesicular bodies are strongly positive for 

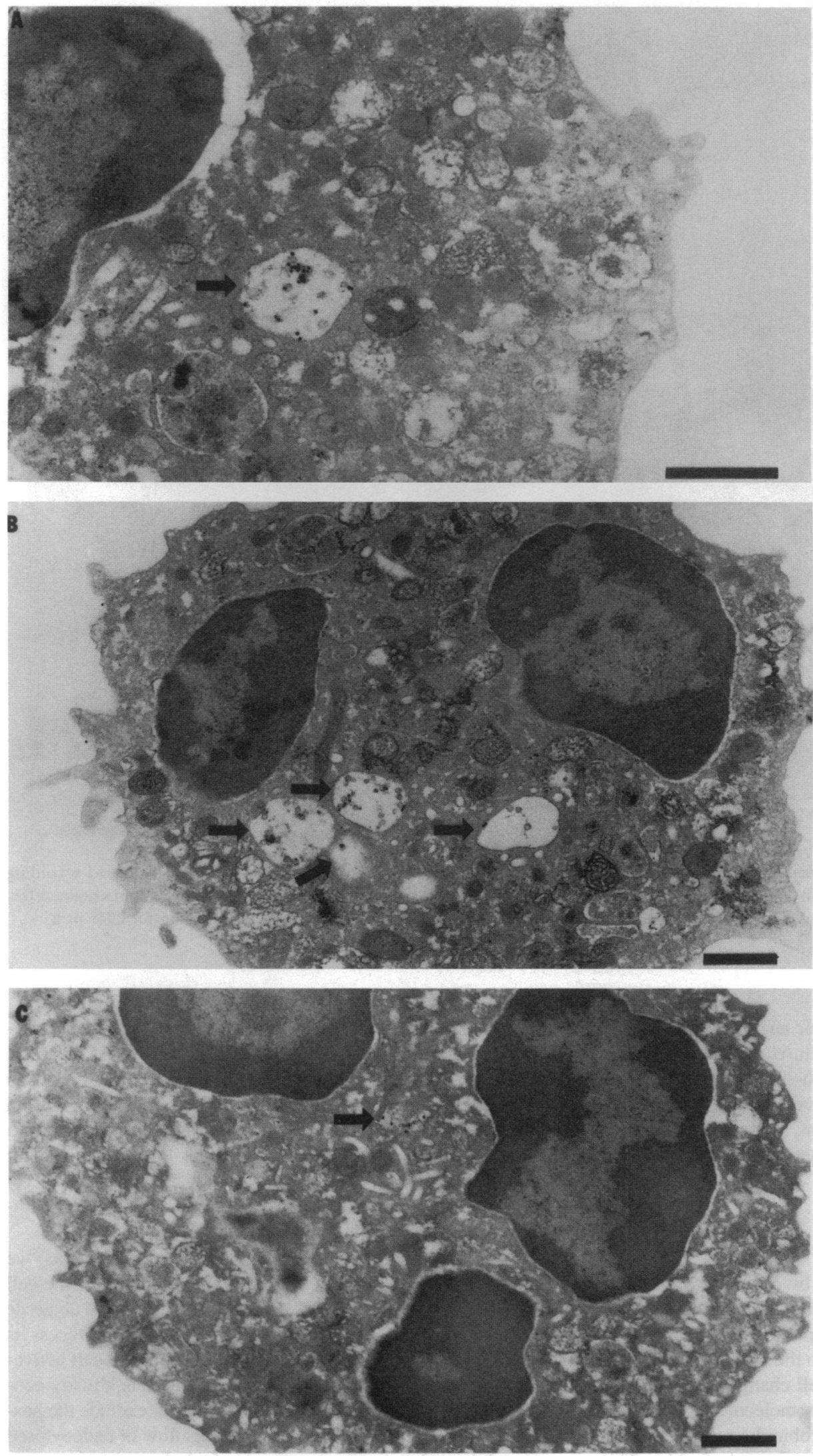

Figure 6. Localization of gold-BSA after 2 min of pulse and $25 \mathrm{~min}$ of chase. ( $A$ and $B$ ) In cells treated with $\mathrm{MLP}$, essentially all of the tracer is now within multivesicular bodies (arrows). (C) In the absence of $f$ MLP, uptake of gold is much less and multivesicular body is much smaller. Bars, $0.5 \mu \mathrm{m}$. 


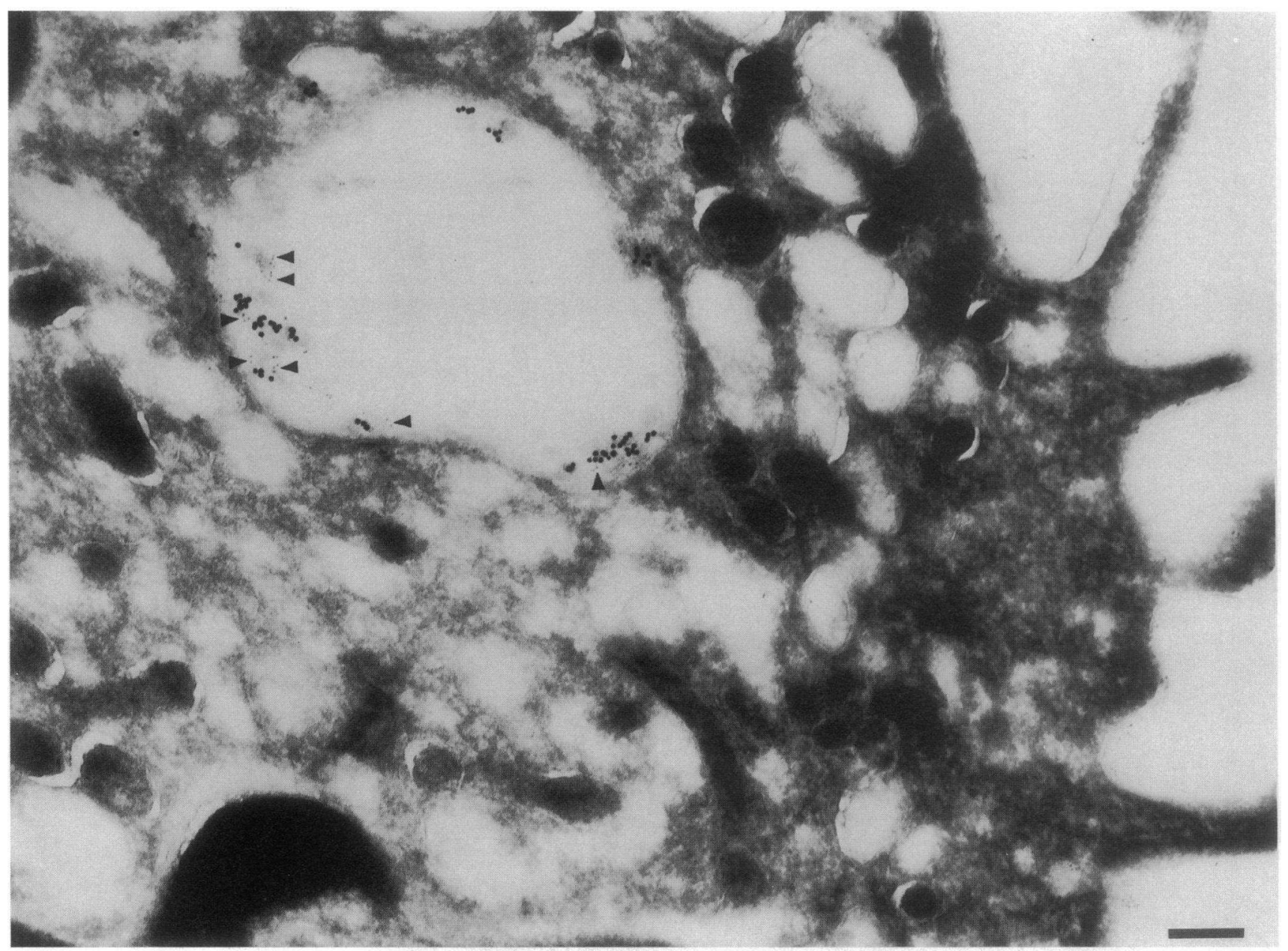

Figure 7. ImmunoEM localization of CR1 and localization of gold-BSA after 2 min of pulse and 25 min of chase. Cells were incubated according to the protocol in Methods, but then fixed in $2 \%$ paraformaldehyde, $0.05 \%$ glutaraldehyde, $0.01 \%$ sucrose. Cryosections were immunostained for CR1 as described above. $20 \mathrm{~nm}$ gold-BSA is the endocytic tracer. $5 \mathrm{~nm}$ gold anti-mouse IgG (arrowheads) indicates staining for CR1 in a multivesicular body. Bar, $0.2 \mu \mathrm{m}$.

hLAMPs (Fig. $13 C$ ). A summary kinetic analysis of the percent of BSA-gold particles per cell in structures staining positively for hLAMPs is provided in Fig. 14. These observations suggest that the multivesicular bodies themselves are the recipients of acid hydrolases, rather than serving as sorting stations from which transport vesicles carry endocytosed material to lysosomes.

\section{Discussion}

Upon activation of human neutrophils by chemoattractants, intracellular vesicles and granules rapidly fuse with the plasma membrane. These structures carry important proteins in their membranes, which are thus delivered to the cell surface. Within minutes, the functional status of the cell changes dramatically, as the surface expression of adhesion molecules, phagocytic receptors, and components of the microbicidal oxidase system increase by an order of magnitude or more $(1-5,11)$. This movement of membrane is not unidirectional-chemoattractant stimulation is also accompanied by a marked increase in the rate of fluid-phase endocytosis $(9,10)$. It seems likely that a major function of the increased endocytosis is to recover membrane and limit the volume to which the cell must increase. Similar membrane retrieval processes have been observed in exocrine gland cells, neurosecretory chromaffin cells and in mast cells (30-32). Previous work on CR1 $(6,12,13)$ and recent data on Fc $\gamma$ RIII (14) suggest that ligand-independent internalization of these receptors accompanies membrane retrieval. In the present investigation, we have defined the pathway and kinetics of this internalization.

Using BSA-gold as a tracer of fluid phase pinocytosis, we found that early endosomes formed at the periphery of the cell and appeared to move rapidly across the cytoplasm and coalesce to form multivesicular bodies. The speed of this process is apparent in the observation that within $10 \mathrm{~min}$ after cell activation, $60-80 \%$ of a pulse of endocytosed tracer is already contained within multivesicular bodies. We cannot exclude the possibility that this rapid movement represents flow of endocytosed material through a continuous system of tubules, with the apparent vesicles representing varicosities formed as the bolus of ingested material moves along the tubule, as has been suggested by others $(33,34)$. Much of the initial internalization occurs 

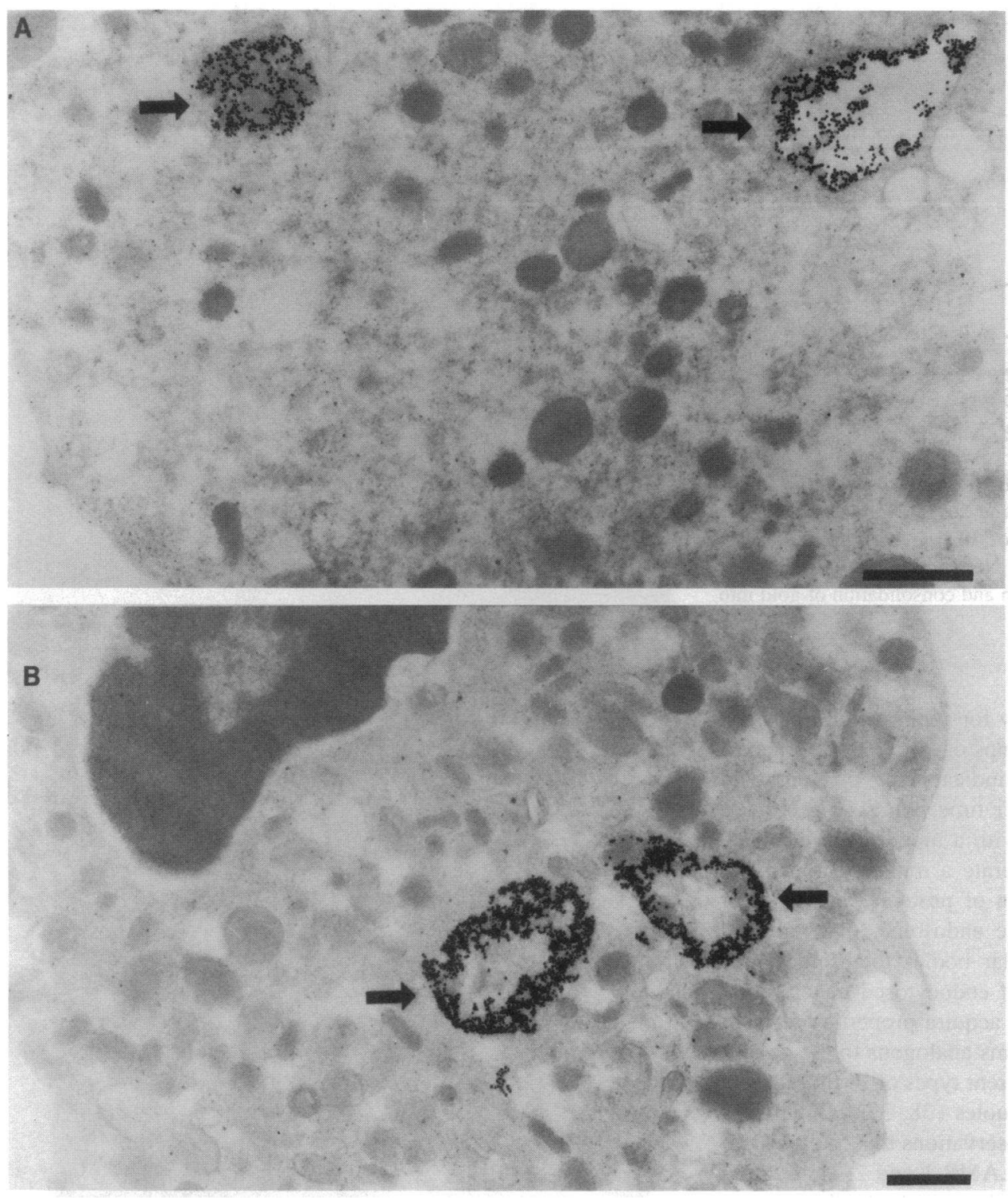

Figure 8. Localization of goldBSA after 2 min of pulse and $1 \mathrm{~h}$ $(A)$ and $4 \mathrm{~h}(B)$ of chase. Bars, $0.5 \mu \mathrm{m}$. A small amount of fine precipitate is visible scattered throughout the cytoplasm, particularly in $A$, but those particles are smaller than and readily distinguishable from the larger goldBSA particles in the mvbs (arrows). in coated areas of membrane even though the uptake of these tracers is not mediated by a specific saturable receptor. Since CR1 colocalizes in these vesicles, these data suggest that this receptor may associate with coated areas of membrane in the absence of cross-linking, as well as when it is cross-linked, as previously reported (35). These data do not exclude the possibility that some of the CR1 is also internalized in non-coated areas of membrane, as reported by Carpentier et al. (12). However, the subsequent pathway may be similar regardless of whether coated or non-coated membrane structures are involved, as suggested by Tran et al. (36).

The small endosomes in which the tracer is initially enclosed and those in which tracer is found deeper in the cytoplasm do not stain positively by DAMP immunocytochemistry, consistent with little or no acidification, and suggesting that their membranes may lack channels or pumps necessary for acidification. Similarly, the initial endosomes do not stain positively for lysosomal membrane proteins, and in fact, the internalization process seems to occur in regions of the cell distant from hLAMP- positive granules or lysosomes. These observations are congruent with those reported by Tougard et al. (19) who used a different anti-lysosomal membrane antibody in rat prolactin cells, but also found that early endosomes did not stain positively. In that study, the first structures in the endocytic pathway to stain positively for lysosomal antigens were multivesicular bodies. Our results are also in agreement with those of Geuze et al. (37) who showed that antibodies against a $120-\mathrm{kD}$ lysosomal membrane protein in rat hepatoma cells progressively labeled endocytic structures, including multivesicular bodies, at 10,30, and $60 \mathrm{~min}$ of endocytosis (37). Judging from images such as Fig. $4 B$, the multivesicular bodies which contain the endocytic tracer may form de novo by the coalescence of early endosomes which are not acidified and are not positive for hLAMP. Our results (Figs. 11-13) suggest that hLAMP-positive granules subsequently fuse with the multivesicular bodies, so that by $1 \mathrm{~h}$ after stimulation the latter are quite clearly positive for hLAMP, suggesting that they probably also contain lysosomal acid hydrolases at that time. By analogy, it seems likely that multivesic- 


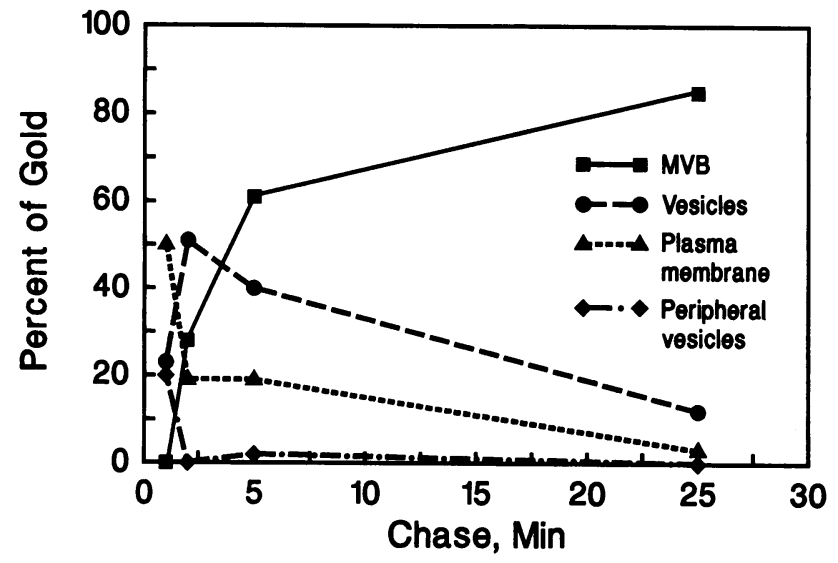

Figure 9. Summary of kinetics of gold-BSA endocytosis. Graph shows mean results from 4-5 sections containing 200-300 gold particles for each time point showing mean percent of total gold particles in each section found in specified compartment. Note rapid uptake into peripheral vesicles and rapidity of translocation and consolidation of gold into multivesicular bodies.

ular bodies also acquire the capacity for acidification by fusion with other vesicles carrying ion pumps or other proteins necessary to lower the internal $\mathrm{pH}$, as indicated by the markedly positive DAMP staining at the later time points (Fig. $10 \mathrm{~B}$ ). These results are most consistent with a model (16) in which the endocytic vesicles fuse to generate a multivesicular body which then matures by the addition of proteins which confer upon it the characteristics of a late endosome. In stimulated neutrophils, these late multivesicular bodies themselves may be important sites of degradation of endocytosed material and membrane proteins since they also acquire properties of lysosomes. This sequence of events seems analogous to the acidification and sequential fusion of different types of PMN granules with newly formed phagocytic vacuoles $(38,39)$. Our results are thus consistent with previous observations that multivesicular bodies in neutrophils contain hLAMP 1 and 2, although in those studies the formation of the multivesicular bodies was not described (40). If these structures serve as prelysosomal sorting sites in stimulated neutrophils, as has been suggested in other cell types $(19,41)$, proteins which are to be recycled without degradation must leave the multivesicular body before the addition of acid hydrolases, as proposed by Felder et al. (17). Our results do not support models (41) which would require transport of CR1 and other proteins that are to be degraded from the multivesicular bodies to separate, pre-existing lysosomes for degradation.

We have previously reported that CR1 undergoes ligandindependent internalization and degradation in chemoattractantstimulated neutrophils (13). By immunofluorescence, one or two large accumulations of CR1 were found in such cells, and incubation with the protease inhibitor PMSF or with $\mathrm{NH}_{4} \mathrm{Cl}$, both of which decreased the degradation of CR1, enhanced the size and increased the staining of these accumulations (13). The present observations are consistent with and explain these earlier data, since we have now demonstrated directly that CR1 colocalizes with the endocytic tracer in early endocytic vesicles and in the newly formed multivesicular bodies that are observed after the cells are stimulated with f MLP. The present results

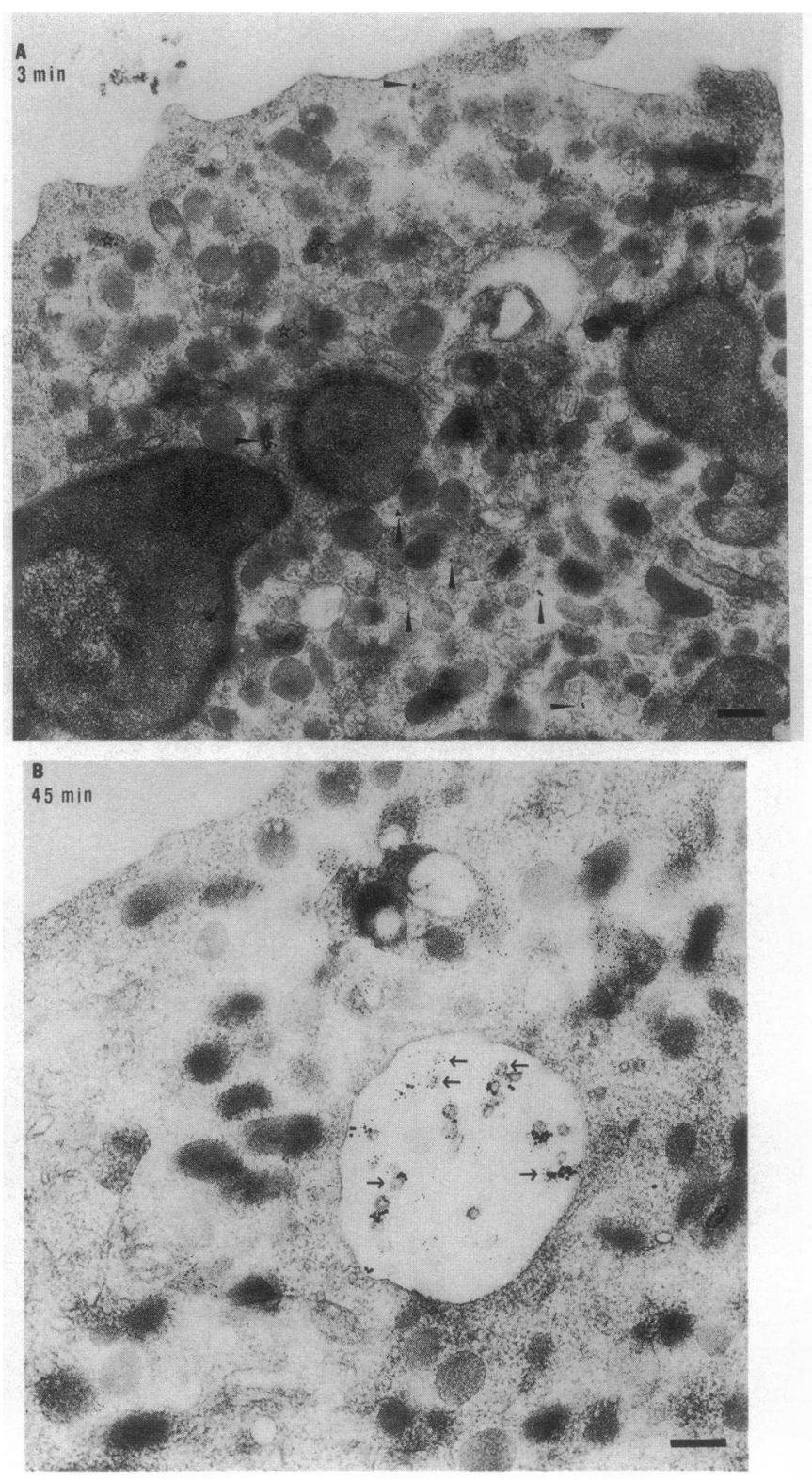

Figure 10. Acidification of endocytic structures. $30 \mu \mathrm{M}$ DAMP was included along with $20 \mathrm{~nm}$ gold-BSA while cells were activated with f MLP. After incubation, cells were fixed by addition of ice-cold $1 \%$ glutaraldehyde in $0.1 \mathrm{M}$ cacodylate, then prepared for EM as described in Methods. ( $A$ ) After 3 min, endocytic vesicles containing $20 \mathrm{~nm}$ goldBSA (arrowheads), whether peripheral, within around $1 \mu \mathrm{m}$ of the plasma membrane, or deep in the cytoplasm do not stain positively for DAMP ( $5 \mathrm{~nm}$ gold). Other types of granules (stars) which do not contain the endocytic tracer do stain positively for DAMP. (B) After 45 min of chase, multivesicular body containing endocytic tracer (20 $\mathrm{nm}$ gold) is also positive for DAMP (detected with $5 \mathrm{~nm}$ gold antiDNP, arrows). Bars, $0.2 \mu \mathrm{m}$.

support our previous speculation that the multivesicular bodies themselves may be the sites of degradation of CR1 (6), since we have now shown that these structures become increasingly acidified and receive lysosomal membrane proteins. It is thus likely that in the earlier immunofluorescence studies, the PMSF and $\mathrm{NH}_{4} \mathrm{Cl}$ induced increase in fluorescent intensity of the large 

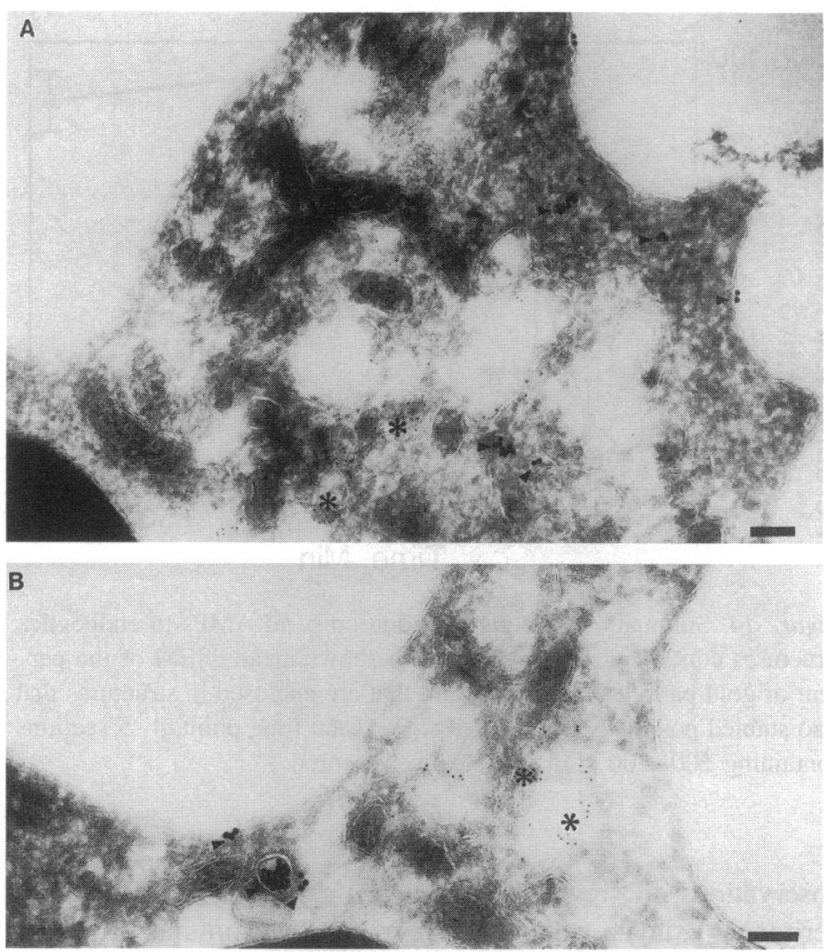

Figure 11. ( $A$ and $B$ ) Localization of lysosomal membrane antigens (hLAMP 1 and 2) after 2 min pulse of endocytosis of gold-BSA. Cryosections of cells incubated for $2 \mathrm{~min}$ with $\mathrm{f}$ MLP and $20 \mathrm{~nm}$ gold-BSA then washed and fixed were immunostained with a mixture of antibodies to hLAMP 1 and 2 . Intracellular granules and vacuoles stain positively for hLAMP with $5 \mathrm{~nm}$ gold as shown by asterixes. Cell membrane and endocytic vesicles containing $20 \mathrm{~nm}$ gold-BSA (arrowheads) do not stain positively for hLAMP. Bars, $0.1 \mu \mathrm{m}$.

positive structures was due to inhibition of degradation of internalized CR1 within multivesicular bodies.

In these studies, we have found that even at intervals as long as $4 \mathrm{~h}$ after the initial "pulse"' of endocytosis, nearly all of the tracer is still contained in a few large multivesicular bodies in each cell, rather than being re-distributed into smaller transport vesicles. Thus, little recycling of content from these structures seems to occur within the time intervals we have studied. It is possible, however, that any recycling vesicles that arise from the large multivesicular bodies move rapidly to the plasma membrane and/or lack endocytic tracer. It is also possible that some membrane proteins are recycled without degradation, by segregation within and removal from the multivesicular bodies before addition of acid hydrolases (17), but that we did not detect this since we did not specifically immunostain for such proteins.

Since the stimulus, $\mathrm{fMLP}$, is present continuously in our "chase" incubations, rapid translocation of intracellular secretory/transport vesicles to the plasma membrane is likely to continue throughout these incubations. Our protocol differs in this respect from that of Jost et al, who did not include a stimulus in their incubations, and who observed co-localization of accumulated endocytic tracer and Fc $\gamma$ RIII in small vesicles in the juxtanuclear region of the cell (14). It is thus possible that in the absence of $\mathrm{ALP}$, when endocytic uptake is slow, individual vesicles rather than multivesicular bodies accumulate over time.
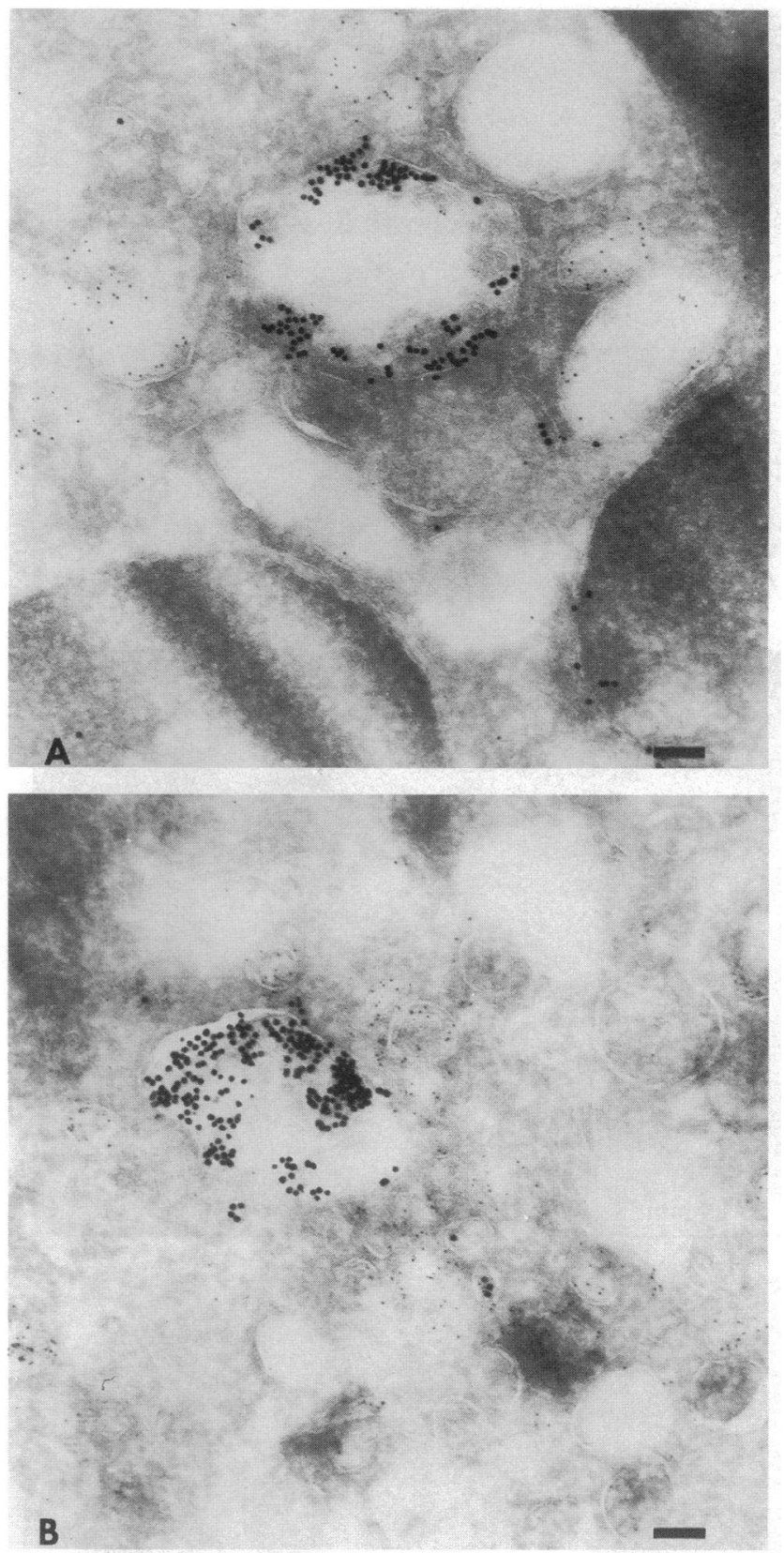

Figure 12. Localization of lysosomal membrane antigens $10 \mathrm{~min}(A)$ and $15 \mathrm{~min}(B)$ after $2 \mathrm{~min}$ pulse of gold-BSA endocytosis. Preparation as in Fig. 11. Intracellular granules and vacuoles staining positively for hLAMP with $5 \mathrm{~nm}$ gold are in proximity of multivesicular bodies containing $20 \mathrm{~nm}$ gold-BSA, but there is little staining of the latter structures for hLAMP. Bars, $0.1 \mu \mathrm{m}$.

If these vesicles also include endocytosed serum protein, one can readily explain the ability of such cells to release serum proteins upon activation, as recently reported by Borregaard et al. (42). This explanation is also suggested by the recent report by Tosi and Zakem (43) that $f$ MLP causes translocation of an intracellular pool of Fc $\gamma$ RIII, presumably in the membranes of the same vesicles, to the plasma membrane. Similar phenomena, and/or bidirectional movement of peripheral vesicles that have not yet fused into multivesicular bodies probably account for the 

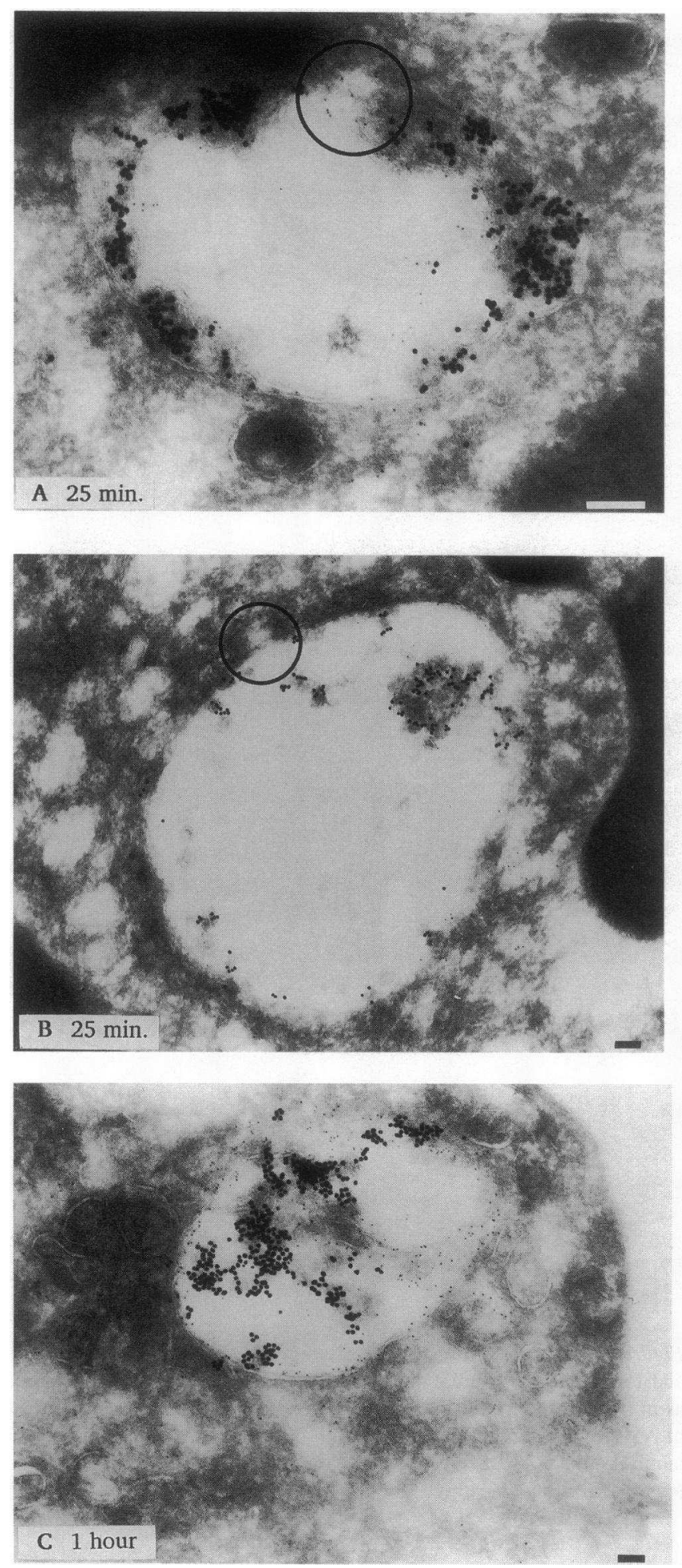

Figure 13. Localization of lysosomal membrane antigens $25 \mathrm{~min}(A$ and $B)$ and $1 \mathrm{~h}(C)$ after 2 min pulse of BSA-gold endocytosis. At 25 min, $(A$ and $B) 20 \mathrm{~nm}$ gold-BSA is present in large multivesicular bodies. Smaller hLAMP positive ( $5 \mathrm{~nm}$ gold) structures appear to be joining the large multivesicular bodies in areas enclosed in circles. After $1 \mathrm{~h}$ of chase, $(C)$ hLAMP ( $5 \mathrm{~nm}$ gold) is present on inner surface of limiting membrane as well as on enclosed vesicles in multivesicular body which is full of endocytic tracer ( $20 \mathrm{~nm}$ gold-BSA). Bars, 0.1 $\mu \mathrm{m}$.

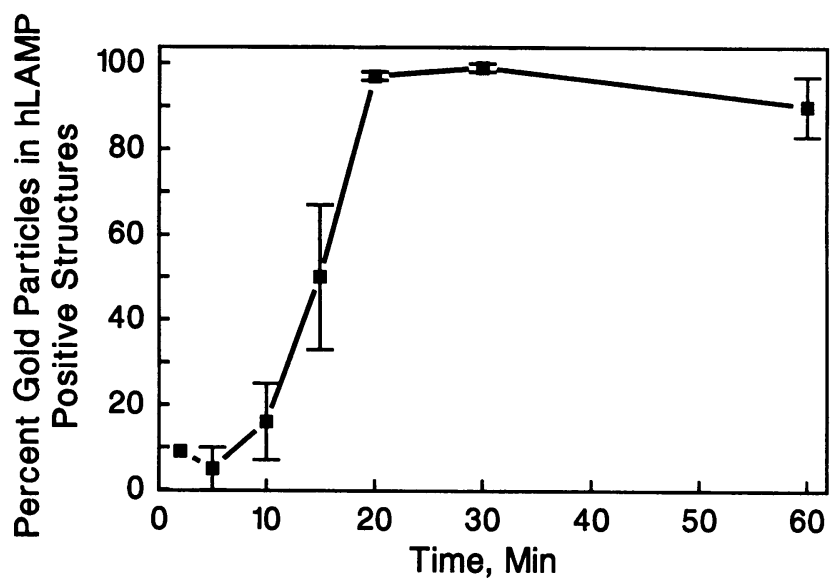

Figure 14. Summary of kinetics of addition of hLAMPs to endocytic structures containing BSA-gold. Graph shows mean \pm SEM of the percent of gold particles in each section that are enclosed in structures that also stained positively for hLAMPs. For each time point, $4-5$ sections containing 200-300 gold particles were scored.

observations of "reversible pinocytosis" by cultured adherent peritoneal exudate cells which were further stimulated by formyl peptide activators ( 8 ).

The rapid increase in the rate of endocytosis upon chemoattractant stimulation makes the neutrophil a useful model which has allowed us to study the formation and maturation of endocytic structures. This system may also be advantageous for determining the mechanisms by which proteins that are recycled without degradation are removed from the multivesicular bodies before acid hydrolases are delivered to them, and for studying the intracellular signals that prompt the intracellular fusion events that lead to maturation of the multivesicular bodies.

\section{Acknowledgments}

The authors wish to thank Joe Polak for his excellent technical support and Christine Wenger Tobias and Rebecca Finney for excellent secretarial support.

This work was supported by National Institutes of Health grants AI22687, RR05410-29, DK38181, and HD62915.

\section{References}

1. Arnaout, M. A., H. Spits, C. Terhorst, J. Pitt, and R. F. Todd. 1984 Deficiency of a leukocyte surface glycoprotein (LFA-1) in two patients with Mol deficiency. J. Clin. Invest. 74:1291-1300.

2. Bainton, D. F., L. J. Miller, T. K. Kishimoto, and T. A. Springer. 1987. Leukocyte adhesion receptors are stored in peroxidase-negative granules of human neutrophils. J. Exp. Med. 166:1641-1653.

3. Berger, M., J. O'Shea, A. S. Cross, T. M. Folks, T. M. Chused, E. J. Brown and M. M. Frank. 1984. Human neutrophils increase expression of C3bi as well as C3b receptors upon activation. J. Clin. Invest. 74:1566-1571.

4. Borregaard, N., L. Christensen, O. W. Bjerrum, H. S. Birgens, and I. Clemmensen. 1990. Identification of a highly mobilizable subset of human neutrophil intracellular vesicles that contains tetranectin and latent alkaline phosphatase. J. Clin. Invest. 85:408-416.

5. Clark, R. A. 1990. The human neutrophil respiratory burst oxidase. $J$. Infect. Dis. 161:1140-1147.

6. Berger, M., E. M. Wetzler, E. Welter, J. R. Turner, and A. M. Tartakoff. 1991. Intracellular sites for storage and recycling of $\mathrm{C} 3 \mathrm{~b}$ receptors in human neutrophils. Proc. Natl. Acad. Sci. USA. 88:3019-3023.

7. Jost, C. R., T. W. Huizinga, R. Goede, J. A. Fransen, P. A. Tetteroo, M. R 
Daha, and L. A. Ginsel. 1990. Intracellular locations and de novo synthesis of FcRIII in human neutrophil granulocytes. Blood. 75:144-151.

8. Daukas, G., D. A. Lauffenburger, and S. Zigmond. 1983. Reversible pinocytosis in polymorphonuclear leukocytes. J. Cell Biol. 96:1642-1650.

9. Davis, B. H., R. J. Walter, C. B. Pearson, E. L. Becker, and J. M. Oliver 1982. Membrane activity and topography of F-Met-Leu-Phe treated polymorphonuclear leukocytes. Am. J. Pathol. 108:206-216.

10. Davis, B. H., E. McCabe, and M. Langweiler. 1986. Characterization of f-Met-Leu-Phe-stimulated fluid pinocytosis in human polymorphonuclear leukocytes by flow cytometry. Cytometry. 7:251-262.

11. Fearon, D. T., and L. A. Collins. 1983. Increased expression of C3b receptors on polymorphonuclear leukocytes induced by chemotactic factors and by purification procedures. J. Immunol. 130:370-375.

12. Carpentier, J. L., D. P. Lew, J. P. Paccaud, R. Gil, B. Lacopetta, M. Kazatchkine, O. Stendahl, and T. Pozzan. 1991. Internalization pathway of C3b receptors in human neutrophils and its transmodulation by chemoattractant receptors stimulation. Cell Regul. 2:41-551.

13. Turner, J. R., A. M. Tartakoff, and M. Berger. 1988. Intracellular degradation of the complement $\mathrm{C} 3 \mathrm{~b} / \mathrm{C} 4 \mathrm{~b}$ Receptor in the absence of ligand. J. Biol. Chem. 63:4914-4920.

14. Jost, C. R., R. deGoede, J. A. M. Fransen, M. R. Daha, and L. A. Ginsel. 1991. On the origin of the FCRIII (CD16)-containing vesicle population in human neutrophil granulocytes. Eur. J. Cell Biol. 54:313-321.

15. Zabucchi, G., R. Menegazzi, M. R. Soranzo, and P. Patriarca. 1986. Uptake of human eosinophil peroxidase by human neutrophils. Am. J. Pathol. 124:510518.

16. Dunn, K. W., and F. R. Maxfield. 1992. Delivery of ligands from sorting endosomes to late endosomes occurs by maturation of sorting endosomes. J. Cell Biol. 117:301-310.

17. Felder, S., K. Miller, G. Moehren, A. Ullrich, J. Schlessinger, and C. R. Hopkins. 1990. Kinase activity controls the sorting of the epidermal growth factor receptor within the multivesicular body. Cell. 61:623-634.

18. Friend, D. S. 1969. Cytochemical staining of multivesicular body and golgi vesicles. J. Cell Biol. 41:269-279.

19. Tougard, C., D. Louvard, R. Picart, and A. Tixier-Vidal 1985. Antibodies against a lysosomal membrane antigen recognize a prelysosomal compartment involved in the endocytic pathway in cultured prolactin cells. J. Cell Biol. 100:786-793.

20. Griffiths, G., and J. Gruenberg. 1991. The arguments for pre-existing early and late endosomes. Trends Cell Biol. 1:5-9.

21. Harbeck, R. J., A. A. Hoffman, S. Redecker, T. Biundo, and J. Kurnick. 1982. The isolation and functional activity of polymorphonuclear leukocytes and lymphocytes separated from whole blood on a single Percoll density gradient. Clin. Immunol. Immunopathol. 23:682-690.

22. Tartakoff, A. P. Vassalli, and R. Montesano. 1981. Plasma cell endocytosis: is it related to immunoglobulin secretion? Eur. J. Cell Biol. 26:188-197.

23. Mane, S. M., L. Marzella, D. F. Bainton, V. K. Holt, Y. Cha, J. E. Hildreth and J. T. August. 1989. Purification and characterization of human lysosomal membrane glycoproteins. Arch. Biochem. Biophys. 268:360-378.

24. Geuze, H. J., J. W. Slot, G. J. Strous, A. Hasilik, and K. Von Figura 1985. Possible pathways for lysosomal enzyme delivery. J. Cell Biol. 101:22532262.

25. Griffiths, G. R., Brands, B. Burke, D. Louvard, and G. Warren. 1982. Viral membrane proteins acquire galactose in trans Golgi cisternae during intracellular transport. J. Cell Biol. 95:781.

26. Tokuyasu, K. T. 1980. Immunocytochemistry on ultrathin frozen sections. J. Histochem. Cytochem. 12:381.

27. Anderson, R. G. W., J. R. Falck, J. L. Goldstein, and M. S. Brown. 1984 Visualization of acidic organelles in intact cells by electron microscopy. Proc Natl. Acad. Sci. USA. 81:4838-4842.

28. Anderson, R. G. W., and R. K. Pathak. 1985. Vesicles and cisternae in the trans golgi apparatus of human fibroblasts are acidic compartments. Cell. 40:635-643.

29. Schwartz, A. L., G. J. Strous, J. W. Slot, and H. J. Geuze. 1985. Immunoelectron microscopic localization of acidic intracellular compartments in hepatoma cells. EMBO (Eur. Mol. Biol. Organ.) J. 4:899-904.

30. Nordmann, J. J., and J. C. Artault. 1992. Membrane retrieval following exocytosis in isolated neurosecretory nerve endings. Neuroscience. 49:201-207.

31. Patzak, A., and H. Winkler. 1986. Exocytotic exposures and recycling of membrane antigens of chromaffin granules: ultrastructural evaluation after immunolabeling. J. Cell Biol. 102:510-515.

32. Thilo, L. 1985. Selective internalization of granule membrane after secretion in mast cells. Proc. Natl. Acad. Sci. USA. 82:1711-1715.

33. Hopkins, C. R., A. Gibson, M. Shipman, and K. Miller. 1990. Movement of internalized ligand-receptor complexes along a continuous endosomal reticulum. Nature (Lond.). 346:335-339.

34. Luo, Z., and J. M. Robinson. 1992. Co-localization of an endocytic marker and acid phosphatase in a tubular/reticular compartment in macrophages. J. Histochem. Cytochem. 40:93-103.

35. Abrahamason, D. A., and M. D. Fearon. 1983. Endocytosis of the C3b receptor of complement within coated pits in human polymorphonuclear leukocytes and monocytes. Lab. Invest. 48:162-168.

36. Tran, D., J. L. Carpentier, F. Sawano, P. Gorden, and L. Orci. 1987. Ligands internalized through coated or noncoated invaginations follow a common intracellular pathway. Proc. Natl. Acad. Sci. USA. 84:7957-7961.

37. Geuze, H. J., W. Stoorvogel, G. J. Strous, J. W. Slot, J. E. Bleekemolen, and I. Mellman. 1988. Sorting of mannose 6-phosphate receptors and lysosomal membrane proteins in endocytic vesicles. J. Cell Biol. 107:2491-2501.

38. Bainton, D. F. 1973. Sequential degranulation of the two types of polymorphonuclear leukocyte granules during phagocytosis of microorganisms. J. Cell Biol. 58:249-264.

39. Jensen, M. S., and Bainton, D. F. 1973. Temporal changes in $\mathrm{pH}$ within the phagocytic vacuole of the polymorphonuclear neutrophilic leukocytes. J. Cell Biol. 56:379-388.

40. Bainton, D. F., and J. T. August. 1988. Multivesicular bodies of human neutrophils (PMN) not granules, immunolabel with the two major lysosomal membrane glycoproteins, hLAMP-1 and hLAMP-2. J. Histochem. Cytochem. 36:953.

41. Miller, K., J. Beardmore, H. Kanety, J. Schlessinger, and C. R. Hopkins 1986. Localization of the epidermal growth factor (EGF) receptor within the endosome of EGF-stimulated epidermoid carcinoma (A431) cells. J. Cell Biol. 102:500-509.

42. Borregaard, N., L. Kjeldsen, K. Rygaard, L. Bastholm, M. H. Nielsen, H. Sengelov, O. W. Bjerrum, and A. H. Johnsen. 1992. Stimulus-dependent secretion of plasma proteins from human neutrophils. J. Clin. Invest. 90:86-96.

43. Tosi, M. F., and H. Zakem. 1992. Surface expression of Fc $\gamma$ RIII (CD16) on Chemoattractant-stimulated neutrophils is determined by both surface shedding and translocation from intracellular storage compartments. J. Clin. Invest. 90:462470. 